\title{
Dimensional Meta-Analysis of Trust: Implications for Covid-19 Communication
}

\author{
Gabriel Pérez Crisanto ${ }^{1 *}$, Cruz García Lirios ${ }^{1}$, José Alfonso Aguilar Fuentes ${ }^{1}$
}

1 Department of Communication, Metropolitan University, CDMX.

*Corresponding Author: Gabriel Pérez Crisanto, Department of Communication, Metropolitan University, CDMX, Mexico.

\section{Received date: September 28, 2021: Accepted date: October 09 2021: Published date: January 03, 2022}

Citation: Gabriel Pérez Crisanto, Cruz García Lirios, José Alfonso Aguilar Fuentes (2022) Dimensional meta-analysis of trust: implications for covid-19 communication. J. Clin Case Rep and Stu 3(1); DOI: 10.31579/2690-8808/093

Copyright: (c) 2022 Gabriel Pérez Crisanto. This is an open access article distributed under the Creative Commons Attribution License, which permits unrestricted use, distribution, and reproduction in any medium, provided the original work is properly cited.

\begin{abstract}
The objective of this work is to review citizen confidence regarding government action in situations of risk and contingency such as the covid-19 coronavirus pandemic. A documentary, meta-analytic and retrospective study was carried out with a selection of sources indexed to international repositories, considering the period from 2010 to 2020 , although the research design limited the results to the research scenario, suggesting the extension of the work towards the relationship between trust and microfinance in the framework of local development.
\end{abstract}

Keywords: meta-analysis, local development, risk, contingency, trust

\section{Introduction}

The Organization for Economic Cooperation and Development in its report for 2020 projects a significant impact of the covid-19 pandemic on developed and emerging economies [1]. Globally, growth of 3\% was expected, but now the best scenario is $1 \%$ and the most feasible $0.5 \%$ [2]. In the case of China, growth of $6 \%$ was expected, but now the best option is $2 \%$ and the most likely thing that will happen is zero growth [3]. Japan projected $0.5 \%$ but its best option will be $-0.5 \%$ to $-3 \%$ [4]. In the same negative trend, the Euro zone awaits its growth options: Italy with $-2 \%$, Germany and France with $-1 \%$, Great Britain, the United States and Spain with $-0.5 \%$ [5].In the framework of this panorama, trust between rulers and ruled is a relevant phenomenon since decisions in contingency situations imply relationships of trust between the parties. In other words, the policies for containing and mitigating a pandemic imply citizens' perceptions and expectations of their rulers, their strategies, and the expected results [6].

In this sense, studies related to civil confidence regarding government action in the face of potential threats to health, warn that risk communication must be transparent, vertical and unilateral, but in the absence of favourable results or the increase in the uncertainty of these mistrust emerges and spreads like a pandemic [7].

Consequently, addressing the phenomenon of trust in the face of a pandemic is crucial to anticipate scenarios of perception, communication, and management of potential health risks, as well as the perceived or expected evaluation of policies such as pandemic containment or mitigation [8].

\subsection{Theory of Trust Expectations}

The structure of perceived trust includes dimensions related to leadership, technology and science [9]. Thus, in the case of the covid-19 coronavirus, the theory explains the trust that citizens place in their political leaders regarding the implementation of science and technology to solve the pandemic [10].

In this way, trust is a tripartite structure that configures an accumulated expectation as a risk approaches or a crisis intensifies [11]. If trust is only attributable to leaders, then a scenario of acquired despair is created in which citizens learn to listen to their leaders but knowing that there is no solution to the problem [12]. In the case that the leaders organize a comprehensive response to the problem and make their decisions based on science and technology, trust is reconfigured into an expectation favourable to global, regional or local identity [13].

In the case of an expected and imminent risk, trust increases when government communication becomes transparent and technical, but if the results are perceived as arising from negligence or ineptitude, then trust transforms emotions of uncertainty, fear, anxiety and anger [14].

In the course of a contingency, after the leaders have established a course of action, trust coexists with emotions and perceptions of risks such as incommensurability, unpredictability and uncontrollability of situations [15]. At that point, risk management is reduced and mistrust increases [16].

However, confidence in science and technology emerges in an imminent risk situation and remains as communication becomes transparent, 
intensifies and technical, but in the absence of perceivable goals, confidence turns into despair or at least unfavourable emotions [17].

However, the trust structure has not been established in situations of maximum risk such as pandemics due to the frequency of their occurrences [18]. Thus, in a scenario of health risks and potential threat to social sectors, the review of the studies is mandatory [19].

\subsection{Studies of Trust Expectations}

The political system in which it is possible to observe the similarities and differences between groups for and against presidential candidates based on processes of negotiation, mediation, conciliation and arbitration around the management and administration of Information Technologies and Communication is known as governance [20]. This is a growing phenomenon as local or federal elections approach and digital networks are exacerbated as instruments for the promotion or dissuasion of a candidate [21].

In the framework of presidential elections, the system of negotiation, mediation, conciliation and arbitration between actors involved in the management and administration of public resources and services is known as governance [22]. In the case of an early electoral contest, governance is a phenomenon that reflects electoral preferences, perceptions of consensus and intentions to vote for parties, candidates and democratic systems [23].

In the case of the effects of the anticipated electoral contest in digital networks such as Facebook, Twitter, YouTube or Instagram, these are assumed as instruments for the promotion of candidates and political platforms [24]. It is a proselytise that generates expectations and voting intentions based on electoral preferences, perhaps established in traditional media such as television, radio, newspapers or films, but when filtered through digital networks, they propitiate a scenario of electoral debate that, for the purposes of the present study allow a diagnosis of the relationship that these determining factors of the elections in the near future [25].

Social psychology, through the models of reasoned action and planned behaviour, has influenced the construction of an information psychology [26]. Both models start from the assumption that behaviour is determined by the relationship between beliefs, attitudes, perceptions and intentions. It is a process that, in the context of the information generated on the Internet, explains consumer decisions based on rational, deliberate, planned and systematic processing [27].

However, psychosocial models have been modified to adjust their relationships to information processing on the Internet. These are the cases of the Technology Acceptance Model, the Trade Adoption Model and the Electronic Consumption Model. These models have incorporated the psychosocial variables of beliefs, attitudes, perceptions and intentions that were proposed to explain efficient, effective and effective behaviour [28].

Although Internet access is concomitant with the increase of users of social networks, these focus on Facebook and twitter not only for ease of use, but also for the usefulness of their protocols when it comes to disseminating personalized information. Social networks are personalized instances of information, but the information disseminated in them requires computational skills, search and information processing skills, as well as storage and dissemination capacities [29].

Consequently, the digital divide involves not only differences between those who access digital media and those who are marginalized or excluded, it connotes differences between Internet users seeking information for their entertainment and Internet users who process information for their knowledge and innovation [30].

Whereby Internet users are attached to a system of academic or professional training that forces them to seek information and process it to show meaningful learning [31].
The relevance of beliefs understood as general categories of information extends to the formation of defined attitudes such as specific categories of information, perceptions of catastrophe risk or perceptions of usefulness of information assumed as expectations that allow to anticipate scenarios of uncertainty, as well as the intentions of using the Internet to most likely process the information that is generated [32].

It is the relationships between the psychosocial variables that make relevant their inclusion in the psychological informational models because they explain the information processing of events distant or close to the daily life of Internet users [33]. In this way, the reception of real-time information is a major factor in planning strategies or lifestyles that lessen the impact of catastrophes [34].

However, the tendency of the informational psychological studies is to specify the psychosocial variables since the beliefs are very general categorizations and could not anticipate specific behaviours, although the attitudes are more delimited categorizations, they require of information perceived to activate decisions of immediate action [35].

Precisely because the intentions are decisive probabilities of carrying out a rational, deliberate, planned and systematic action, they predict the emergence of behaviour, but the information generated on the Internet leads to a more emotional than rational process [36].

It is for this reason that the study of intentions with emotional and rational dimensions seems to be more pertinent in an unpredictable and incommensurable scenario as would be the electoral contests [37].

However, digital networks as a framework of agendas, advertisements, opinions, preferences and intentions, represent a small percentage of the electorate that will participate in the elections [38]. This is because unlike traditional media, digital networks not only reproduce information but also produce expectations in potential voters [39].

Such a difference between the Internet, television, radio, the press or cinema makes it necessary to reflect on the studies of mass communication centred on the establishment of agenda, the framing effect and its consequences on the intentions to vote [40]. That is to say that the study of the digital networks supposes a differentiation of sectors even among the users of Facebook, Twitter, YouTube and Instagram with respect to others of digital networks [41].

Therefore, it is necessary to study in greater depth the study of the similarities and differences of internet users of digital networks with respect to potential voters of the elections in question [42].

\subsection{Specification a model for study of trust expectations}

From the theoretical, conceptual and empirical frameworks of trust, it is possible to delineate the axes, trajectories and relationships between the variables. In this way, how the trust towards the authorities regarding their strategies in the face of the covid-19 coronavirus pandemic would be structured in dimensions related to the propensity to decisions, but aversion to the results.

The propensity for decisions and the aversion to results configure an ambivalent phenomenon that prevails in the face of risks, contingencies and expected threats. Decision-making, as established in the theory of trust, involves a structure of expectations based on costs and benefits. In the case of the pandemic, the decisions of the actors involved will be established based on expectations of high losses and low profits. That is to say, the political leaders when declaring the confinement of the people as an instrument of contention or mitigation of the pandemic assume; 1) the smallest number of infections and deaths to reduce economic effects provided that 2) institutions, organizations and political and social actors are willing to reduce or limit their resources and capacities. 
The structure of propensity for decisions contrasts with the configuration of aversion to results. It is a flow of contradictory expectations since a consensus of propensity to decisions prevails derived from universal identity, national union or community solidarity, but contrary to the results that for some actors are usually minimal, insufficient or improvable.

In this scenario, leaders seek to preserve their reputation and prestige. Meanwhile, followers question the results, warning that decisions and results depend on the degree of process innovation rather than optimization of resources. Or, the opposite if the prospective decision is to generate new opportunities. In this sense, strategies for a pandemic are more widely accepted during a crisis, although this social support decreases as infection progresses and deaths increase.

\section{Method}

A documentary, retrospective and exploratory study was carried out with a selection of sources indexed to international repositories; Ebsco, latindez, Scielo, Scopus and WoS, considering the publication period from 2010 to 2020, as well as the keywords of expectations and risks, as well as the use of the Confidence Expectation Scale, which includes seven items related to the intentions of rulers with respect to the civil protection of the governed in the event of risk events (see Table 1).

Note: Elaborated with data study.

\begin{tabular}{|l|l|l|l|l|}
\hline Indexing & Year & Author & $\mathrm{N}$ & Load \\
\hline & & & & \\
\hline Ebsco & 2019 & Villegas & 125 &, 46 \\
\hline Latindex & 2019 & Bucio & 130 &, 38 \\
\hline Scielo & 2019 & Juarez & 140 &, 42 \\
\hline Scopus & 2019 & Bustos & 100 &, 50 \\
\hline WoS & 2019 & Sanchez & 120 &, 39 \\
\hline Ebsco & 2020 & Limon & 100 &, 47 \\
\hline Scielo & 2019 & Aldana & 110 &, 37 \\
\hline Latindex & 2019 & Bermudez & 130 &, 49 \\
\hline Ebsco & 2019 & Rosas & 100 &, 51 \\
\hline Ebsco & 2019 & Hernandez & 140 &, 61 \\
\hline Latindex & 2020 & Quiroz & 100 &, 60 \\
\hline
\end{tabular}

Table 1. Prospective dimension of the Confidence Expectation Scale

A search was conducted at www.scholar.google.com considering the key expectations, confidence and risks. Expert judges selected the studies, considering the theoretical and conceptual dimensions of propensity to decisions and aversion to results, as well as the factor loads of these dimensions in a common factor identified as expectations of trust, consensus perspective or perception of agreement. Data were coded as type A literature for studies reporting the preponderance of both dimensions; Type B literature for the works that included both variables with other dimensions such as transparency and accountability. The data were processed in the systematic reviews and meta-analysis software version 3.0 considering the descriptive, contingent and proportional statistics of probability of making decisions at thresholds of permissible risk.

\section{Results}

Table 2 shows the analysis of homogeneous random effects of propensity for decisions in contingencies; sample size, effect sizes, confidence intervals, significance level, variance, standard deviation and confidence intervals in the thresholds of permissible decision-propensity.

\begin{tabular}{|l|l|l|l|l|l|l|l|}
\hline Author & $\mathbf{N}$ & $\mathbf{E S}$ & $\mathbf{L L}$ & $\mathbf{U L}$ & sig & $\mathbf{V}$ & SE \\
\hline Villegas & 125 &, 12 &, 05 &, 19 &, 000 &, 03 &, 11 \\
\hline Bucio & 130 &, 20 &, 10 &, 24 &, 000 &, 03 &, 12 \\
\hline Juarez & 140 &, 30 &, 07 &, 26 &, 000 &, 03 &, 12 \\
\hline Bustos & 100 &, 45 &, 22 &, 30 &, 000 &, 03 &, 12 \\
\hline Sanchez & 120 &, 56 &, 20 &, 35 &, 000 &, 03 &, 11 \\
\hline Limon & 100 &, 70 &, 25 &, 40 &, 000 &, 03 &, 11 \\
\hline Aldana & 110 &, 34 &, 14 &, 25 &, 000 &, 03 &, 12 \\
\hline Bermudez & 130 &, 73 &, 17 &, 46 &, 000 &, 03 &, 11 \\
\hline Rosas & 100 &, 64 &, 10 &, 53 &, 000 &, 05 &, 25 \\
\hline Hernandez & 140 &, 43 &, 11 &, 62 &, 000 &, 06 &, 36 \\
\hline Quiroz & 100 &, 22 &, 06 &, 39 &, 000 &, 04 &, 16 \\
\hline
\end{tabular}

Note: Elaborated with data study: $N=$ Sample Size, ES = Erects Size, LL = Lower Limit, UL = Upper Limit, sig = significance level, V = variance, $S E=$ Standard Error

Table 2. Analysis of the weight of the prospective dimension in the Confidence Expectations Scale.

The meta-analytic data allowed the estimation of proportional probability values. These permissible risk thresholds suggest that expectations of confidence are in a zone of social tolerance. In other words, the studies that used the Decision Propensity Scale seem to show a tenuous distance between citizen support for the authorities and their rejection of the decisions they made in risky situations, more specifically in the contingency phase.

\section{Discussion}

The contribution of this work to the state of the question lies in the establishment of risk thresholds after a systematic review of studies that 
used the Confidence Expectations Scale. The results obtained are limited by the criteria for choosing research that used the scale, the review period and the journal indexing. This suggests the extension of the review in other periods, repositories and dimensions related to the Confidence Expectations Scale.

In relation to the confidence expectations theory, which proposes two dimensions, one related to the prospective decision and the other alluding to the expected results, the present work has established a threshold in which the values of the systematic review were included. Research lines concerning the observation of meta-analytic values in other periods and repositories will allow observing the threshold found.

Regarding the prospective dimension which indicates the commitment of high risks to obtain low profits in an uncertain or threatening environment, the present study has established a threshold in which the studies systematically reviewed are uncertain in a permissible or tolerable zone relative to expectations. Trust worthy. Research regarding this prospective dimension will allow us to observe the same threshold for works that used the same scale in different contexts.

Regarding the aversive dimension of the Confidence Expectations Scale, which highlights the dissent among the parties involved, this paper warns that the prospective dimension could be unrelated. This is so because risk communication is not a continuous process but an emergent and therefore disruptive one. Studies that corroborate this assumption will allow establishing a threshold perceived as tolerable for those who expect decisions and actions from their authorities.

\section{Conclusion}

The objective of the present work was to establish confidence expectations thresholds in the event of risk events. In the case of the prospective dimension, the present study established the threshold considering a revision from 2010 to 2020 , indexation and factor load. These results are limited by these constraints and suggest extension to another period of time and type of repository. In relation to the theoretical framework, the established threshold suggests an allowable risk, although this would probably not be associated with the threshold of the aversive dimension.

\section{References}

1. World Health Organization (2020). Impacto de la crisis financiera y económica mundial en la salud. New york: who

2. Panamerican Health Organization (2020) health and new international economic order. New york: paho

3. Akerstrom, N. (2001). Undecidability of decision. Copenhagen: mpp

4. Aldana, W. (2016). Especificación de un modelo para el estudio de las redes colaborativas en una universidad productora del conocimiento. Civilizar, 18 (35), 91-102

5. Arigela, A. K. (2013). Model based prospective decision support system for informatic security. International journal of scientific engineering \& technology rsearch, 2 (14), 1515-1522

6. Bermudez, G. (2019). Meta-analitycal validity of the social entrepreneurship inventory: a study of random effects size. Global journal of manaagement 19 (10), 15-19

7. Bermudez, G. (2019). Flexibilidad sociopolítica en la economia 4,0. Revista ciencia política, 37, 1-10

8. Bond, S. D. (2008). Generating objectives: can decision makers articulate what they whant? Management science, 54 (1), 56-70

9. Bouls, B. (2020). Specification of a model of entrepreneurship: from opportunism to innovation. International journal of advances research, 8 (3), 20-24

10. Bucio, C. (2019). Estructura factorial exploratoria del emprendimiento caficultor en una localidad del centro de mexico. Integración académica en psicología, 7 (20), 111-127

11. Bustos, j. (2019). Meta-analysis randomized bivariate effects of governance on common resources management. Journal social science rsearch, 7 (9), 1-9

12. Bustos, J. M. (2018). Contrastación de un modelo de decisión prospectiva e implicaciones para una gobernanza universitaria de la sustentabilidad. Revista trabajo social, 23 81), 1-10

13. Carreon, J. (2018). Modelamiento del emprendimiento internauta en una universidad pública del centro de mexico mediante el analisis factorial exploratorio. Divulgación de la investigación, 16 (1), 1-16

14. Carreon, J. (2019). Categorical exploratory structure of intellectual capital formation in its phase of intangible organizational assests. Journal of social science research, 6 (8), $1-10$

15. Carreon, J. (2019). Model of the determinants of human capital. International journal of advances in social sciences \& humanities, 7 (8), 1-5

16. Cervantes, M. I. (2019). Reliability and validity of the scale of labor welfare. Frontiers, 18 (31), 1-21

17. Cheng, P. Y. (2014). Decision utility and anticipate discrete emotions: an investment decision model. Journal behavioral finance, 15 (2), 1-10

18. Clark, S. (2020). Specification of a model of intellectual capital. International journal of economics \& management studies, 10 (3), 1-3

19. Garcia, C. (2005). El modelo de decisión prospectiva. Reme, 1 (1), 1-10

20. Garcia, C. (2013). La red de conocimiento en una universidad con sistema de practias profesionales y servicio social tecnológico-administrativo. Fundamentos en humanidades, 14 (1), 135-157

21. Garcia, C. (2019). Agenda of knowledge management. Akademia, 18 (1), 1-10

22. Garcia, C. (2019). Gobernanza prospectiva mnetropolitana. Drussendroff: eae

23. Garcia, C. (2020). Model of intangible assests and capitals in organizations. Journal fo neurology, psychiatry and brains research, 20 (1), 1-9

24. Garcia, C. (2020). Specification a model for study of commitement entrepreneurship. Journal of scientific research \& report, $10(1), 1-13$

25. Garcia, C. (2020). Specification a model for study of intellectual capital. Journal of business in organization, 3 (1), 1-4

26. Garcia, C. (2020). Specification a model for study of utility entrepreneurship. Global journal of human social science, 20 (1), 35-38

27. Garcia, C. (2020). Specification a model of knowlwdge. International journal of engineering, technology \& management research, 7 (2), 1-6

28. Garcia, C. (2020). Specification a model of latest organizational. Journal of geography, environments \& earth science internatiuonal, 10 (1), 1-6

29. Hernandez, J. (2018). Modelo de cibercultura organizacional en la innovación del conocimiento. Vision gerencial, 18 (2), 235253

30. Hernandez, J. (2019). Decisión prospectiva opttimizadora e innovadora. Eureka, 16 (2), 127-143

31. Juarez, M. (2020). Specification a model for study of cooperate asistence. Global journal of archeology \& anthropology, 11 (2), $50-54$

32. Limon, G. A. (2020). Specification of a model of nedd information about covid 19 coronavirus. International journal of social science studies, 8 (6), 1-5 
33. Mendyk, A. (2010). Decision support systems for ppharmaceutical formulation development based on artificial neural networks. Decision support systems, 100, 99-123

34. . Global advanced rsearch journal of agricultural sciences, 8 (10), 1-4Owen, G. S. (2012). Clinical assesment of decision making capacity in acquired brain injury with personality change. Neuropsychological rehabilitation, 20, 1-17

35. Quiroz, C. Y. (2019). Specification a model of culture knowledge management

36. Rosas, F. J. (2019). Contrastación de un modelo de decisión prospectiva de la sustentabilidad. Invurnus, 14 (2), 9-19

37. Sanchez, A. (2019). Confiabilidad y validez de un instrumento que mide la gestión del conocimiento. Espacios en blanco, 30, 922

38. Saruni, D. (2018). Naïve bayes optimization based on particle swarm optimization to predict the decision of insurance customer canddidate. International journal of computer technique 5 (5), 814

39. Saruni, D. (2018). Utilization of prediction data for prospective decision customer insurance using the clasification method of c45 and naïve bayes algorithms. Journal of physics. 11 (79), 1-9

40. Streb, J. M. (2011). Estabilización económica e incentivos políticos. Buenos aires: ucema

41. Villegas, E. (2018). Establecimiento de una política de ciencia y tecnología para la incubación de microempresas innovadoras del conocimiento. Inclusiones, 5, 19-26

42. Villegas, E. (2019). Specification a model for study of the perception of knowledge. Open journal political science, 9 (1), $1-6$
This work is licensed under Creative Commons Attribution 4.0 License

To Submit Your Article Click Here:

Submit Manuscript
DOI: $10.31579 / 2690-8808 / 093$
Ready to submit your research? Choose Auctores and benefit from:

$>$ fast, convenient online submission

$>$ rigorous peer review by experienced research in your field

$>$ rapid publication on acceptance

$>$ authors retain copyrights

$>$ unique DOI for all articles

$>$ immediate, unrestricted online access

At Auctores, research is always in progress.

Learn more https://auctoresonline.org/journals/journal-of-clinical-case-reportsand-studies 